\title{
ANALISA KEDIP TEGANGAN PADA SALURAN UDARA 20 KV AKIBAT GANGGUAN TIGA PHASA BERDASARKAN JENIS KONDUKTOR PENYULANG
}

\author{
Hendi Matalata \\ Dosen Jurusan Teknik Listrik, Fakultas Teknik Universitas Batanghari \\ e-mail : hendi.matalata@unbari.ac.id
}

\begin{abstract}
ABSTRAK
Sistem tenga listrik dapat dikatakan memiliki keandalan yang tinggi apabila sistem tersebut menyediakan pasoka energi listrik yang dibutuhkan konsumen secara kontinyu, pada kenyataannya permasalahan yang dihadapi penyaluran sistem tenaga listrik adalah gangguan kedip tegangan (voltage sags) yang diakibatkan gangguan hubung singkat pada sisi penyulang, Penelitian ini menganalisa kedip tegangan yang terjadi pada Saluran Udara Tegangan Menengah (SUTM) 20 KV akibat gangguan hubung singkat tiga phasa berdasarkan jenis konduktor yang digunakan pada sisi penyulang, kajian dilakukan dengan asumsi sistem penyaluran tanpa gardu hubung dan menggunakan konduktor AAC dan AAAC. Hasil penelitian menunjukan besar magnitud arus ganggan hubung singkat tiga phasa pada kedua konduktor menyerupai disepanjang penyulang, sedangkan besar kedip tegangan yang terjadi disepanjang penyulang menyerupai jika terjadi gangguan dititik $0 \%-10 \%$ panjang penyulang dan terdapat perbedaan besar kedip tegangan apabila gangguan terjadi diatas $25 \%$ panjang penyulang. Hasil dari penelitian ini dapat digunakan untuk keperluan penyetelan proteksi pada sisi penyulang dalam menjaga keamanan dari penyaluran energi listrik.
\end{abstract}

Kata Kunci : Hubung Singkat,AAC,AAAC dan Kedip Tegangan

\section{PENDAHULUAN}

Sistem penyaluran tenaga listrik dari pembangkit tenaga listrik ke konsumen sangat penting untuk dipelajari karena proses penyalurannya melalui beberapa tahap yaitu mulai dari pembangkit tenaga listrik yang menghasilkan energi listrik, disalurkan ke jaringan transmisi Saluran Udara Tegangan Tinggi (SUTT) langsung ke gardu induk, dari gardu induk tenaga listrik disalurkan ke jaringan distribusi primer Saluran Udara Tegangan Menengah (SUTM), biasanya saluran ini energi listrik sudah dimanfaatkan industri berkapasitas besar. Melalui jaringan SUTM ini tenaga listrik disalurkan melalui gardu distribusi sekunder Saluran Udara Tegangan Rendah (SUTR) dan melalui SUTR tenaga listrik di salurkan ke konsumen.

Jaringan Distribusi adalah bagian dari sistem tenaga listrik yang menyalurkan tenaga listrik dari gardu induk, dimana penyalurannya menggunakan konduktor saluran kabel melalui saluran udara. Gangguan-gangguan yang dialami oleh jaringan yang terpasang pada saluran udara tegangan menengah $20 \mathrm{KV}$, adalah gangguan-gangguan diakibatkan oleh petir, binatang dan pohon yang terkena jaringan tenaga listrik sehingga dapat menimbulkan gangguan 1 phasa ketanah, gangguan 2 phasa dan gangguan 3 phasa, akibatnya penyaluran tenaga listrik terganggu atau mengalami pemadaman[1]. Analisa hubung singkat adalah bagian dari sistem tenaga listrik, guna menjaga keamanan dari penyaluran energi listrik. perlu memperhitungakan besar arus gangguan hubung singkat untuk keperluan penyetelan proteksi pada sisi penyulang.

Pada peneltian ini dilakukan kajian kedip tegangan (voltage sags) yang diakibatkan gangguan hubung singkat tiga phasa berdasarkan jenis konduktor pada sisi penyulang, dimana konduktor yang 
digunakan adalah AAC (All Aluminium Conductor) dan AAAC (All Aluminium Alloy Conductor).

\section{TINJAUAN PUSTAKA}

Kedip tegangan yang terjadi akibat gangguan hubung singkat tiga phasa menggunakan persamaan sebagai berikut[1]:

\subsection{Gangguan Hubung Singkat Tiga Phasa}

Pada gangguan hubung singkat tiga phasa yang harus diperhatikan adalah impendansi yang digunakan yaitu impedansi urutan positif nilai ekivalen $\left(Z_{1}\right)$ dan tegangan yang digunakan tegangan phasa $\left(\mathrm{V}_{\mathrm{ph}}\right)$.

$$
\begin{aligned}
\mathrm{Z}_{1} \text { ekivalen }= & \mathrm{Z}_{1} \text { sumber }+\mathrm{Z}_{1} \text { trafo } \\
& +\mathrm{Z}_{1} \text { penyulang }
\end{aligned}
$$

$V_{p h}=\frac{V_{p h-p h}}{\sqrt{3}}$

$\mathbf{I}_{3 \mathbf{p h}}=\frac{\left(\mathbf{V}_{\mathbf{p h}-\mathbf{p h}}\right) / \sqrt{\mathbf{3}}}{\left(\mathbf{Z}_{1 \text { ekivalen }}\right)}$

$\mathbf{I}_{\mathbf{3 p h}}=\frac{\left(\mathbf{V}_{\mathbf{p h}-\mathbf{p h}}\right) / \sqrt{\mathbf{3}}}{\left(\mathbf{R}_{\mathbf{1}}+\mathbf{j} \mathbf{X}_{\mathbf{1}}\right)}$

$I_{3 p h}=\frac{V_{p h}}{\left(\sqrt{\left(R_{1 j a r}\right)^{2}+\left(X_{1 G}+X_{1 T}+X_{1 j a r}\right)^{2}}\right)}$

$\mathbf{X}_{1 \mathrm{G}}=\frac{\left(\mathrm{V}_{\text {sekunder }}\right)^{2}}{\text { MVA }_{\text {hubung singkat }}}$

$\mathrm{X}_{1 \mathrm{~T}}=\frac{\left(\mathrm{V}_{\text {sekunder }}\right)^{2}}{\mathrm{MVA}_{\text {trafo }}} \mathbf{X} \%$ reaktansi trafo

dimana :

$\mathrm{I}_{3 \mathrm{ph}}=$ arus gangguan tiga phasa (Amper)

$\mathrm{R}_{1 \mathrm{jar}}=$ resistansi urutan positif jaringan $(\mathrm{Ohm} / \mathrm{Km})$
$\mathrm{X}_{1 \mathrm{G}}=$ reaktansi induktif urutan positif generator pembangkit (Ohm)

$\mathrm{X}_{1 \mathrm{~T}}=$ reaktansi induktif urutan positif trafo (Ohm)

$\mathrm{X}_{1 \mathrm{jar}}=$ reaktansi induktif urutan positif jaringan $(\mathrm{Ohm} / \mathrm{Km})$

\subsection{Kedip Tegangan (voltage sags)}

$$
\text { Vkedip }=\sqrt{\left(j r k H S * r_{\text {sal }}\right)^{2}+\left(j r k H S * x_{\text {sal }}\right)^{2}} x I_{3 \phi} x \sqrt{3}
$$

dimana :

jrk HS adalah jarak ketika terjadi hubung Singkat 3 phasa

$\mathrm{r}_{\mathrm{sal}}$ adalah resistansi jaringan

$\mathrm{x}_{\text {sal }}$ adalah reaktansi jaringan

$\mathrm{I}_{3 \phi}$ adalah arus gangguan hubung singkat 3 phasa

\subsection{Konduktor Saluran 20 KV}

Pada konduktor AAC (All Aluminium Conductor) dan AAAC (All Aluminium Alloy Conductor) saluran $20 \mathrm{KV}$, untuk luas penampang $240 \mathrm{~mm}^{2}$, GMR (Geometric Mean Radius) 6,6238 mm. Impedansi kawat penghantar menurut SPLN 64 : 1995 diperlihatkan pada Tabel $1[2]$.

Tabel 1. Impedansi Konduktor

AAC (All Aluminium Conductor)

\begin{tabular}{lll}
\hline $\begin{array}{l}\text { Luas } \\
\text { Penampang } \\
\left(\mathrm{mm}^{2}\right)\end{array}$ & $\begin{array}{l}\text { Impedansi } \\
\text { urutan Posotif } \\
(\mathrm{Ohm} / \mathrm{Km})\end{array}$ & $\begin{array}{l}\text { Impedansi urutan } \\
\text { Nol }(\mathrm{Ohm} / \mathrm{Km})\end{array}$ \\
240 & $0,1225+\mathrm{j} 0,3157$ & $0,2705+\mathrm{j} 1,6032$ \\
\hline
\end{tabular}

AAAC (All Aluminium Alloy Conductor).

\begin{tabular}{lll}
\hline $\begin{array}{l}\text { Luas } \\
\text { Penampang } \\
\left(\mathrm{mm}^{2}\right)\end{array}$ & $\begin{array}{l}\text { Impedansi } \\
\text { urutan Posotif } \\
(\mathrm{Ohm} / \mathrm{Km})\end{array}$ & $\begin{array}{l}\text { Impedansi urutan } \\
\text { Nol }(\mathrm{Ohm} / \mathrm{Km})\end{array}$ \\
240 & $0,1344+\mathrm{j} 0,3158$ & $0,2824+\mathrm{j} 1,6034$ \\
\hline
\end{tabular}

\section{METODOLOGI}

Penelitian ini mengkaji kedip tegangan pada sistem penyaluran $20 \mathrm{KV}$ akibat gangguan tiga phasa, tanpa gardu 
hubung. SingleLine kajian penelitian ini di tunjukan pada gambar 1. dibawah.

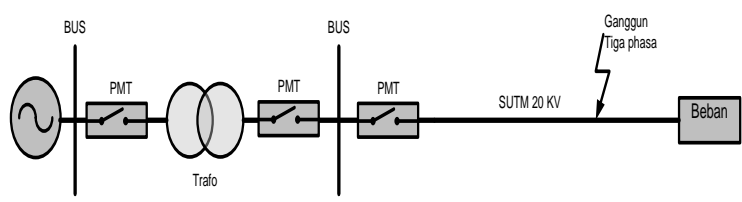

Gambar 1. SingleLine Gangguan Satu Phasa Ke Tanah Pada Sisi Penyulang

Untuk mengkaji kedip tegangan di sisi penyulang maka terlebih dahulu menghitung besar arus gangguan hubung singkat. Tujuan perhitungan gangguan hubung singkat adalah untuk menghitung magnitud arus hubung singkat maksimum dan minimum, sehingga dapat menentukan besar kedip tegangan yang terjadi disepanjang penyulang[3].

\subsection{Model Alur Penelitian}

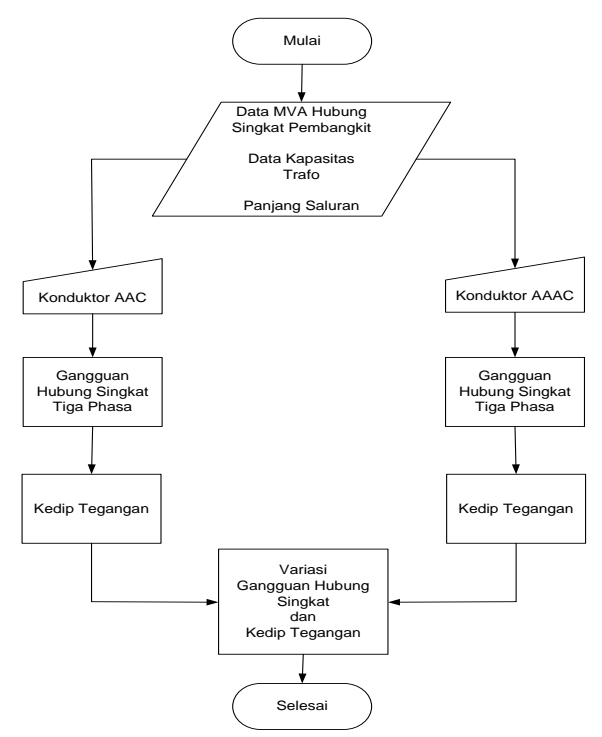

Gambar 2. Alur Penelitian

\subsection{Parameter - parameter Penelitian}

Data yang di jadikan parameter untuk analisa kedip tegangan adalah data Trafo, data penyulang $20 \mathrm{KV}$ dan MVA hubung singkat sisi pembangkit, dimana titik gangguan berada pada $25 \%$ dan $75 \%$ dari panjang penyulang menggunakan konduktor AAC dan konduktor AAAC, berikut asumsi parameter kajian penelitian yang dilakukan:

Tabel 1. Asumsi Data Kajian Penelitian

\begin{tabular}{ll}
\hline \multicolumn{2}{c}{ DATA TRAFO } \\
\hline Daya & $60 \mathrm{MVA}$ \\
Tegangan Sekunder & $150 \mathrm{KV}$ \\
Tegangan Primer & $20 \mathrm{KV}$ \\
Rasio CT Trafo Tenaga & $2000 / 5$ \\
Hubungan Delta Trafo & Ada \\
Kapasitas Belitan Delta & $20 \mathrm{MVA}$ \\
Reaktansi (\%) & 12 \\
Ground Resistor & 40 \\
Rasio CT (trafo arus) & $300 / 5$ \\
\hline \multicolumn{2}{c}{ DATA PENYULANG (SUTM 20 KV) } \\
\hline Panjang Penyulang & $10 \mathrm{Km}$ \\
AAC & $240 \mathrm{~mm}^{2}$ \\
AAAC & $240 \mathrm{~mm}^{2}$ \\
\hline \multicolumn{2}{c}{ PEMBANGKT } \\
\hline MVA Hubung Singkat & $4547 \mathrm{MVA}^{2}$ \\
Arus Beban & $280 \mathrm{Amper}^{2}$ \\
\hline
\end{tabular}

\section{HASIL DAN PEMBAHASAN}

Hasil penelitian ini didapat dari perhitungan dengan bantuan Software MATLAB menggunakan skrip m.file pada MATLAB (pure script)[4], dimana proses perhitungan dilakukan secara manual berdasarkan persamaan matematis yang dibahas pada Bab sebelumnya.

Sebelum melakukan perhitungan besar kedip tegangan, langkah pertama yang dilakukan adalah menghitung besar arus hubung singkat tiga phasa pada masing-masing konduktor yang digunakan (AAC dan AAAC). Magnitud besar arus gangguan hubung singkat dari kedua jenis konduktor diperlihatkan pada gambar 3 dan gambar 4 dibawah.

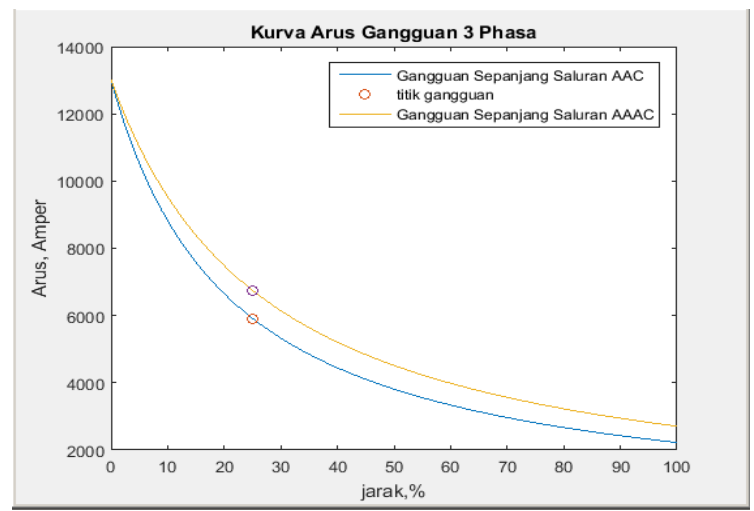

Gambar 3. Kurva Gangguan Hubung Singkat Tiga Phasa Dititik Gangguan 25\% Sepanjang Saluran 
Pada gambar 3 diatas terdapat Gangguan hubung singkat tiga phasa sepanjang saluran antara konduktor AAC dan AAAC dimana besar magnitud arus gangguan pada titik $25 \%$ panjang penyulang didapat masing-masing 5.917,3 Amper dan 6.749 Amper. Sedangkan gangguan yang terjadi di titik $75 \%$ diperlihatkan pada gambar 4 dibawah.

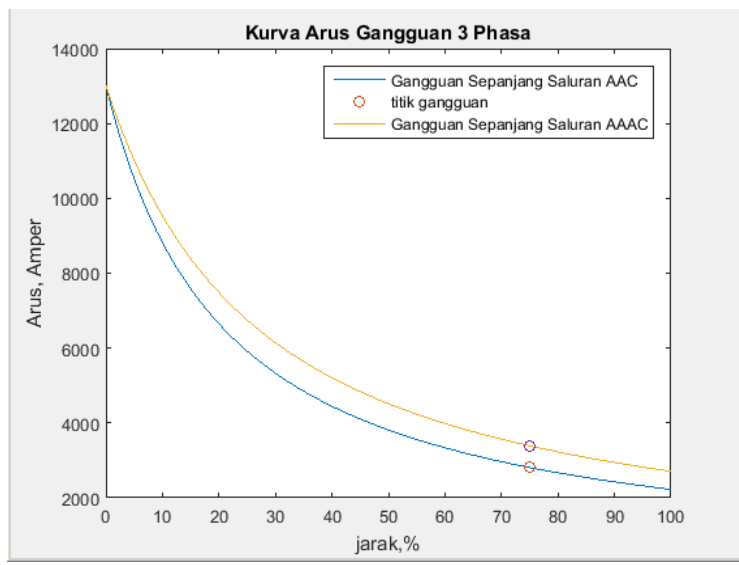

Gambar 4. Kurva Gangguan Hubung Singkat Tiga

Phasa Dititik Gangguan 75\% Sepanjang Saluran

Gambar 4 diatas memperlihatkan magnitud arus gangguan hubung singkat tiga phasa sepanjang saluran antara konduktor AAC dan AAAC pada titik $75 \%$ panjang penyulang, masing-masing besar magnitud arus gangguan adalah 2.809,7 Amper dan 3.387,3 Amper. Analisa kedip tegangan dari kedua titik gangguan, 25\% dan $75 \%$ panjang penyulang dari masingmasing konduktor jika terjadi gangguan tiga phasa diperlihatkan pada gambar 5 dan gambar 6 dibawah.

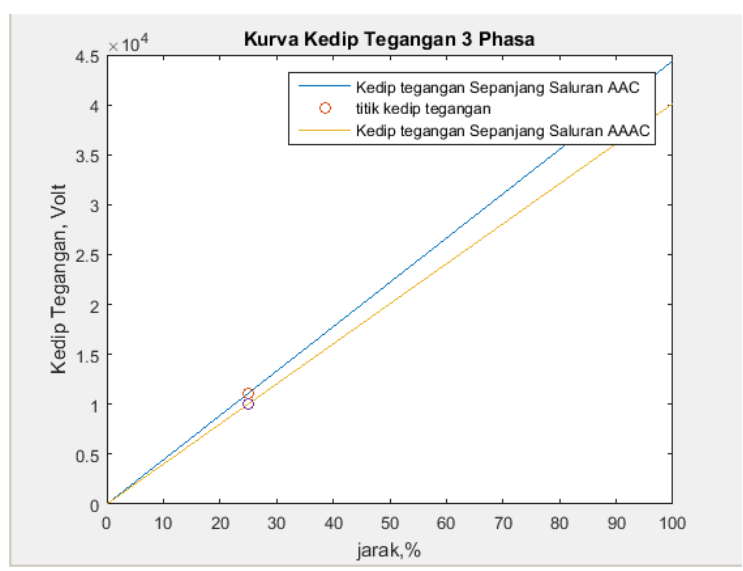

Gambar 5. Kurva Kedip Tegangan Dititik 25\% Sepanjang Saluran
Kedip tegangan pada titik gangguan $25 \%$ panjang penyulang yang diperlihatkan pada gambar 5 diatas didapat masingmasing 11.104 Volt dan 10.031 Volt . Sedangkan kedip tegangan pada titik gangguan $75 \%$ diperlihatkan pada gambar 6 dibawah.

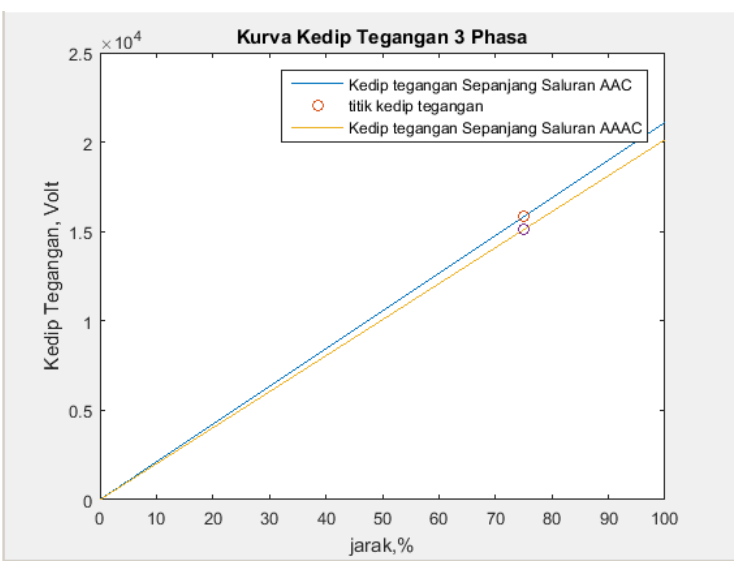

Gambar 6. Kurva Kedip Tegangan Dititik 75\% Sepanjang Saluran

Gambar 6 diatas memperlihatkan besar kedip tegangan di titik gangguan $75 \%$ antara kedua konduktor masing-masing 15.818 Volt dan 15.102 Volt

\section{KESIMPULAN}

Dari analisa perhitungan yang dilakukan, besar kedip tegangan yang didapat dari masing-masing konduktor dapat disimpulkan sebagai berikut:

1. Besar magnitud arus hubung singkat tiga phasa pada Konduktor AAC dan Konduktor AAAC terjadi perbedaan satu sama lain jika terjadi gangguan di sepanjang penyulang.

2. Besar kedip tegangan menyerupai jika terjadi gangguan dititik $0 \%$ sampai $10 \%$ panjang penyulang

3. Terdapat perbedaan besar kedip tegangan dari titik gangguan 25\% sampai $100 \%$ panjang penyulang

4. Besar kedip tegangan dapat digunakan sebagai acuan pada sistem proteksi sisi penyulang 


\section{DAFTAR PUSTAKA}

[1] Pribadi.K dan Wahyudi.S, Pelatihan Proteksi Distribusi, Udiklat Padang, PT PLN (Persero), 2005

[2] Impedansi Kawat Penghantar Menurut SPLN 64:1995

[3] I Made.Y.D, I Wayan.R dan I Made.S, Analisa Kedip Tegangan Akibat Gangguan Hubung Singkat Pada Penyulang Abang Di Karang Asem, E-Journal SPEKTRUM Vol.3, No.2, 2016

[4] MATLAB User's Guide, The Mathwork, inc, 1989.

[5] M.W.Nasution,Teguh.Y dan Ontoseno.P, Pengaruh Kedip Tegangan dan Koodinasi Rele Arus Lebih pada Pabrik Semen, Jurnal Teknik ITS Vol.1, No.1, 2012 